\title{
Gregor SAMSA, el SUjeto DIVIDIDO $^{1}$
}

\section{Gregor Samsa, the Split Subject}

\author{
SANDra Viviana Gómez Rubio ${ }^{2}$
}

Recibido: 2018-10-05 Aceptado: 2018-12-18

\begin{abstract}
Resumen: En este artículo utilizaré el texto literario La transformación de Franz Kafka para analizar la figura narrativa de Gregor Samsa desde los registros imaginario, simbólico y real, con el propósito de evidenciar la división del sujeto Gregor, siendo este personaje —este ser- uno de los tantos objetos posibles del psicoanálisis en la literatura. Recurriré a Hegel para comprender el reconocimiento y la constitución de la autoconciencia, a Freud para entender la similitud entre la creación literaria y la ensońación, y a Lacan, quien asume el inconsciente como lenguaje y al sujeto como el efecto de la interpelación del lenguaje.
\end{abstract}

Palabras clave: transformación, cuerpo, real, imaginario, simbólico.

\begin{abstract}
In this article I will use the literary text "The Transformation” by Franz Kafka, to analyze Gregor Samsa as a narrative figure from the imaginary, symbolic and real registers. The motive is to make evident the Gregor's subject division, being this character (as a being) one of the many possible objects of psychoanalysis in the literature. Therefore, I will appeal to Hegel to understand the knowledge and the constitution of the selfconsciousness, to Freud to understand the similarity between literary creation and the dream, and to Lacan who assumes the unconsciousness as a language and, likewise, the subject like the effect of the interpellation of the language.
\end{abstract}

Keywords: transformation, body, real, imaginary, symbolic.
Para citar este artículo en APA: Gómez, S. (2018). Gregor Samsa, el sujeto dividido. Revista de Psicología Universidad de Antioquia, 10(2), 203- 223.

DOI: 10.17533/udea. rp.v10n2a09
1. Artículo de reflexión derivado de la investigación «El sujeto en La transformación" para optar al título de Licenciada en Filosofía.

2. Licenciada en Filosofía. Universidad Pedagógica Nacional, Bogotá, Colombia. Correo:1fl_svgomezr438@pedagogica.edu.co; http://orcid.org/0000-0002-9835-6923. 


\section{Introducción}

En este trabajo el lector encontrará un análisis del texto La transformación, más específicamente sobre lo que le ocurre al personaje principal: Gregor Samsa, un hombre común y corriente que un día amanece convertido en un monstruoso bicho. Primero, haré ciertas especificaciones sobre la traducción de ciertos conceptos; segundo, me remitiré a las nociones de reconocimiento y estadio del espejo para hablar de la identificación imaginaria del personaje; tercero, evidenciaré la pérdida paulatina-que sufre Gregor-del vínculo con el otro y, además, su goce de la palabra interna; y cuarto, mostraré que la transformación es sintomática al ser un desbordamiento de lo real. Esto me llevará a concluir que la creación literaria está impulsada, en cierta medida, por el inconsciente, lo cual puede constituir un aporte al campo tanto de la psicología como del psicoanálisis, disciplinas que se ocupan de la mente humana desde caminos singulares pero emparentados.

\section{El enigma del bicho Gregor}

La transformación o Die Verwandlung, por Franz Kafka, es el escrito literario protagonista de este artículo, particularmente el personaje de Gregor Samsa, pues es el ser que sufre distintas adversidades. Me referiré a la historia a la que el narrador da vida, quien es una figura discursiva que posiciona actores -Gregor es uno de ellos-, cuyas acciones constituyen la historia de vida que suscitó este mismo texto.

Las primeras palabras del Die Verwandlung, en el idioma original, son: «Als Gregor Samsa eines Morgens aus unruhigen Träumen erwachte, fand er sich in seinem Bett zu einem ungeheueren Ungeziefer verwandelt» (Kafka, 2004, p. 96) ${ }^{1}$. Lo que en español sería: «Cuando, una mañana, Gregor Samsa se despertó de unos sueños agitados, se encontró en su cama transformado en un bicho monstruoso» (Kafka, 2012, p. 19). La traducción más próxima a mi interpretación de la palabra Ungeziefer es bicho y no insecto, lo cual denota

\footnotetext{
La cursiva es propia.
} 
que es más ambiguo y difícil de determinar cuál es específicamente el animal en el que Gregor se convierte. Considero que esa es una característica propia del texto: mantener el enigma de la figuración de Gregor. De hecho, el propio Kafka en una carta enviada al editor Kurt Wolff — uno de los primeros en publicar sus manuscritos- dice:

Me escribieron ustedes últimamente que Ottomar Starke realizará la ilustración para la cubierta de La transformación [...] quizá esté en su deseo querer dibujar el mismísimo insecto. ¡Esto no, por favor! No quisiera reducir su poder de influencia, sino sólo exponer un deseo, debido a mi evidente mejor conocimiento de la historia. El insecto mismo no puede ser dibujado. Ni tan solo debe ser mostrado desde lejos... Si yo mismo pudiera proponer algún tema para la ilustración, escogería temas como: los padres y el gerente ante la puerta cerrada, o, mejor todavía: los padres y la hermana en la habitación fuertemente iluminada, mientras la puerta hacia el sombrío cuarto contiguo se encuentra abierta (Kafka, 2012, pp. 112-13).

En últimas, se termina publicando el texto con la siguiente ilustración en la cubierta:

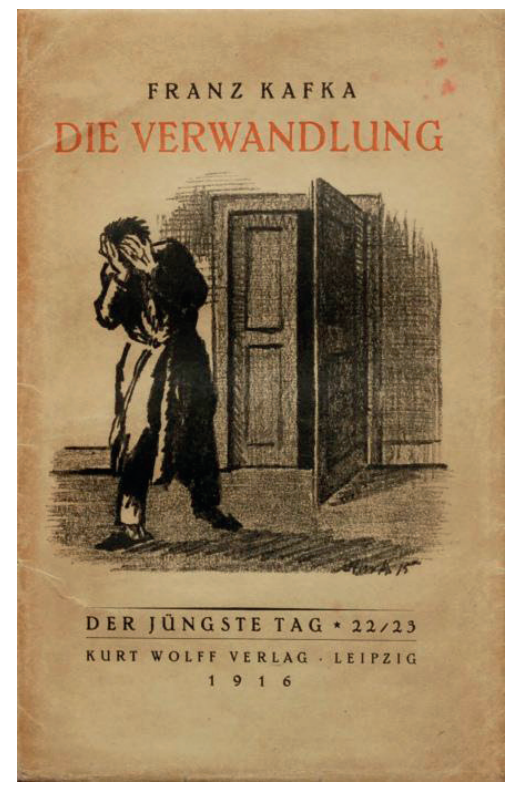

Alt, P.-A., como se cita en Wetter (2015) 
Sin lugar a dudas, fue una decisión muy acertada que la primera ilustración de La transformación haya sido una persona ocultando su rostro y su mirada como efecto de haber observado algo horroroso, espantoso. De ese modo, salió victoriosa la posición de Kafka de que el bicho no figure; de entrada, el lector que se acerque por primera vez a este texto podrá anticiparse y creer que lo que está dentro de esa habitación es algo aterrador y desdeñable.

Ahora bien, traduzco Die Verwandlung por La transformación ${ }^{2}$ y no como se conoce comúnmente: La metamorfosis, ya que la palabra metamorfosis se refiere al proceso biológico por el que atraviesa un animal para llegar a un estado de madurez o adultez, proceso que implica diversos y fundamentales cambios fisiológicos y comportamentales. Veamos la definición de la palabra "metamorfosis":

Del latín metamorphōsis y del griego $\mu \varepsilon \tau \alpha \mu o ́ \rho \varphi \omega \sigma ı \varsigma ~$

En biología, estadio del ciclo vital de muchos invertebrados, la mayoría de anfibios y ciertos peces, durante el cual estos experimentan una serie de cambios que implican una variación sustancial de su morfología y hábitos, junto a una reconstitución de sus tejidos. En zoología, conjunto de modificaciones morfológicas y estructurales que tiene lugar en el desarrollo postembrionario de algunos animales, como los insectos y los batracios (BioDic, 2019).

En consecuencia, para los propósitos de este texto hablaré de una transformación y no de una metamorfosis, porque esta última alude a un proceso biológico constante y gradual. Transformación, en cambio, se asemeja mucho más al cambio abrupto que le ocurrió a Gregor. De ahí que no se conciba a Gregor como un escarabajo, pese a que ésta sea la consideración popular, posiblemente influenciada por el hecho de que en toda la historia la sirvienta sea la única que ose asemejarlo a un escarabajo: «Komme mal herüber, alter Mistkäfer!» (Kafka, 1996, p. 80) o «Seht mal den alten Mistkäfer!» (1996, p. 145). Que corresponde a: «iVen aquí, viejo escarabajo!», o «iMira el viejo escarabajo!» (Kafka, 2010, p. 83).

2. Ya Borges (1983) había dicho: «Yo traduje el libro de cuentos cuyo primer título es La transformación y nunca supe por qué a todos les dio por ponerle La metamorfosis. Es un disparate, yo no sé a quién se le ocurrió traducir así esa palabra del más sencillo alemán. Cuando trabajé la obra el editor insistió en dejarla así porque ya se había hecho famosa y se la vinculaba a Kafka». 


\section{El reconocimiento y el estadio del espejo}

Gregor muestra una fractura en la identificación de su cuerpo en el registro imaginario. Él es un empleado más que fortuitamente despierta un día convertido en un bicho, mas pareciese que no es a él al que le ocurre dicho evento esporádico porque, pese a que sus patas revolotean y no tiene control sobre ellas, no puede dejar de lado que debe ir a trabajar y que es necesario que abandone todas esas locuras y se prepare para alcanzar el próximo tren. Para comprender el resquebrajamiento de la identificación imaginaria de su cuerpo hablemos, primero, del reconocimiento y, segundo, del estadio del espejo.

Hegel en la Fenomenología del espiritu (1966) planteará que toda conciencia dice "Yo", esto es, una conciencia que es consciente de sí; en otros términos, la conciencia de sí es autoconciencia y se manifiesta a través de la palabra «yo». No obstante, decir «yo» refiere a todos los «yo» posibles, razón por la cual la experiencia de la autoconciencia es la determinación exacta de su yo, de su singularidad.

Algo que por constitución define al yo es la apetencia como mecanismo de impulso general. El yo es puro apetito porque para ese yo que es autoconciencia los objetos son algo negativo, es decir, son algo que la autoconciencia puede apropiarse o devorar. Así, la realización del yo está en la apetencia pues toma el objeto y se lo apropia, lo domina, lo somete, lo supera, lo disuelve, lo devora. La apetencia es, por lo tanto, el acto de realización del yo. Y como la superación del objeto es la realización de la apetencia, la conciencia descubre que para poder realizar su yo necesita del otro: el otro es quien le da su reconocimiento, su estatuto. Entonces, ¿en quién podría reconocerse Gregor luego de la transformación?

La autoconciencia no es sólo una conciencia que se sabe a sí misma, sino que son dos conciencias, justamente, que se saben a sí mismas: «La autoconciencia sólo alcanza su satisfacción en otra autoconciencia» (Hegel, 1966, p. 112). La autoconciencia es un producto colectivo... es el juego de las diversas conciencias relacionándose entre sí. De ahí que la autoconciencia tenga tres momentos — lógicos, no ontológicos—: 1) el yo, 2) la apetencia — de un objeto que resulta ser autoconciencia-, y 3) otra autoconciencia. 
La conciencia solamente es en tanto se la reconoce. La escena de la conciencia y la autoconciencia, del descubrimiento de la conciencia por medio del reconocimiento que le da otra conciencia, se constituye como fundamento de la estructura posible del hablar. En la relación el otro es también un objeto, un objeto de apetencia. Empero, el estatuto del otro como cuerpo en el cual puedo desplegar mi apetencia es distinto del reconocimiento del otro como un objeto que no es autoconsciente. Ahora bien, si Gregor es consciente de sí -en cuanto piensa-, ¿por qué no puede controlar su cuerpo?

Denominaré registro imaginario al juego de fuerzas en el que se sumerge la autoconciencia con otra autoconciencia, a partir de lo cual cada una supone un estatuto de «sí misma». De esa manera, el otro es susceptible de ser amado porque es aquel de quien tomo el estatuto de ser, pero, al mismo tiempo, el otro es susceptible de ser odiado, no sólo debido a que la conciencia prueba su estatuto propio como independiente del otro en la agresión, sino principalmente porque el no-reconocimiento del otro me borra como conciencia. Por lo tanto, el registro imaginario presentifica simultáneamente la posibilidad de agresión al otro. Esta agresión no es natural, ni es inducida: es un efecto de la relación imaginaria y, desde entonces, es parte de nuestra condición como seres hablantes.

Somos objetos para el otro cuando se trata de la apetencia, pero a condición de ser seres — cuerpos- hablantes. Esto ocurre a condición de que el otro — nos - hable. El otro es, por consiguiente, alguien que sustenta y a su vez atenta con la estabilidad o la unidad imaginaria — mi conciencia-; por eso, el otro es también un enemigo que debe ser superado, devorado...

La existencia de esta inclinación agresiva que podemos registrar en nosotros mismos y, con derecho, presuponemos en los demás es el factor que perturba nuestros vínculos con el prójimo y que compele a la cultura a realizar su gasto [de energía] (Freud, 1979b, p. 109).

Podría pensarse que Gregor causa aversión porque nadie puede reconocerse en él, no hay par con el cual él pueda identificarse. ¿¿Será la transformación una suerte de objeción de Gregor al reconocimiento? «Innumerables patas, lamentablemente escuálidas en comparación con el grosor ordinario de sus piernas, ofrecían a sus ojos el espectáculo de una agitación sin consistencia». 
(Kafka, 1974, p. 7). Según el narrador, la transformación deja a Gregor sin el dominio de su propio cuerpo, aunque su «conciencia»se mantenga. El texto trastoca la supuesta «unidad» entre conciencia y cuerpo.

\footnotetext{
Para incorporarse, podía haberse ayudado de los brazos y las manos; mas, en su lugar tenía ahora innumerables patas en constante agitación y le era imposible hacerse dueño de ellas. Y el caso es que él quería incorporarse. Se estiraba; lograba por fin dominar una de sus patas; pero, mientras tanto, las demás proseguían su libre y dolorosa agitación. (Kafka, 1974, p. 14).
}

Ante la imposibilidad de controlar y reconocer sus miembros, habría que enunciar una pérdida de síntesis o de unidad que — se presupone - constituye a un sujeto. Gregor expresa una ruptura en el cuerpo que se había «dado a sí mismo", pues su transformación pone en cuestión la síntesis o la unión entre la conciencia y el cuerpo.

En El estadio del espejo (2008) Lacan explica cómo un infante, en algún momento de su vida, al posicionarse frente a un espejo reconoce que la imagen proyectada por éste le pertenece en la medida en que es él quien la genera. Ese instante de reconocimiento de sí mismo en el espejo es un acontecimiento que conlleva asombro y fascinación en el infante, pues, ¿`cómo algo que se presenta externamente a él es, de hecho, él mismo? Reconocerse en el espejo es la ocasión en la que hace de una imagen externa, de otro, la presentificación de sí mismo. Allí, en este proceso esporádico, él se representa a sí mismo como un ser unitario, pues eso es lo que muestra el espejo: un cuerpo. Entonces, dicho infante se precipita a una identificación por vía de la imagen, es decir, a una identificación imaginaria.

Ahora bien, ¿qué pasó con la identificación imaginaria de Gregor luego de la transformación? Cuando él despierta como bicho sigue teniendo conciencia de sí, aunque no controla su nueva corporeidad.

Durante los primeros ańos de vida del nińo ocurre un evento que marca un hito en su desarrollo como persona: cuando su reflejo frente al espejo no le es indiferente. Ese instante — de carácter sorpresivo - marca la pauta en el que éste se reconoce a sí mismo a través de la imagen en el espejo. La imagen que ve ya no le resulta, entonces, ajena a sí mismo. 
El niño, dado que no es un sujeto epistémico, no se concentra en el objeto-imagen para aprehenderlo, sino que tiene que pasar por diversas instancias hasta llegar a constituirse como sujeto. Para mayor comprensión, hablaré de momentos, pero no presuponiendo un ordenamiento cronológico u ontológico, sino lógico.

En un primer momento, cuando el niño se ubica de cara al espejo, la imagen reflejada le es totalmente indiferente. Cuando éste observa lo que proyecta el espejo no se ve a sí mismo, sino algo externo a él, porque aún no está constituido aquello que podríamos llamar «sí mismo», es decir, el sujeto. En otras palabras, el humano «recién nacido» no se concentra en la imagen como un objeto cognoscible, sino que se inclina por ciertas cosas en función de sus instintos. Se está haciendo alusión, pues, a la dinámica más simple en la que se encuentra el nińo previamente a ser configurado como un sujeto.

En un segundo momento, el niño se precipita sobre la imagen, pues carece de aquello — la unidad — que ella presenta, atribuyéndole esa consistencia que escenifica la imagen del espejo a sí mismo. Como la imagen ya no le es indiferente, le otorga, por el contrario, una consistencia al niño, dado que éste obtiene de ella eso que él no tiene: corporeidad, en el sentido del reconocimiento de su cuerpo a través de la imagen, lo que se consolida en un tercer momento cuando el niño se reconoce en la imagen. Antes no sabía que él era la imagen, pero a partir del reconocimiento él se vuelve la imagen, se vuelve eso otro, esto es, se atribuye a sí mismo aquello que tiene consistencia, o bien, un cuerpo; momento en el cual puede hablarse, de hecho, de un «sí mismo». Así pues, este acontecimiento discontinuo da como resultado la formación del sujeto como efecto de la identificación con la imagen. Por ende, el sujeto empieza a surgir como sujeto cognoscente a través del reconocimiento. Este reconocimiento es un acontecimiento discontinuo que produce alborozo y causa una suerte de exaltación.

En suma, el estadio del espejo se comprende como la identificación que recae en el sujeto cuando se identifica con la imagen proyectada en el espejo. El sujeto se hace una imagen de su cuerpo, una imagen que se muestra como unidad. Cuando el niño se ve al espejo, ve una consistencia que él no tiene, una imagen con la que posteriormente se identificará. La identificación imaginaria 
es, entonces, el proceso mediante el cual nos hacemos un cuerpo, pero es un cuerpo imaginario. Por esa razón consideramos que Gregor «hizo» el cuerpo de la transformación, conllevando el resquebrajamiento de la identificación imaginaria previa a ser un bicho.

De manera que ese instante de identificación erige un yo -moi- como construcción imaginaria que predispone, paralelamente, a la construcción de un yo - je-como posición simbólica del sujeto. Esto quiere decir que el efecto que se produce de un cuerpo imaginario como constitutivo de un yo - moi- dispone al sujeto a un lugar de enunciación, el cual instaura la dimensión simbólica del sujeto donde se constituye un yo - je-. En este momento, el sujeto construye la imagen de su propio cuerpo a través de la imagen que este se figura del cuerpo de otro. Dicho de otro modo, la identificación con la imagen es la identificación con el otro; el mundo posible — por así decirlo- de un sujeto está en ese hecho fortuito de identificación, puesto que la adquisición de la imagen del otro es al mismo tiempo la adquisición del propio cuerpo. Ahora bien, si «soy eso que está allá», de entrada, soy algo alienado.

Siguiendo a Hegel, ¿podemos decir que, una vez producido el reconocimiento, no hay vuelta atrás? ¿Queda el reconocimiento sólo como condición inicial? Esto no se ajusta con el registro imaginario: la consistencia de la imagen ha de ser sostenida reiteradamente. El cuerpo del protagonista no se presta para que el otro encuentre un reconocimiento; sin embargo, él todavía se reconoce en los otros, pese a la transformación. Si fuera un escarabajo, se reconocería instintivamente con otro escarabajo — algo fundamental durante el cortejo, por ejemplo_-; igual si fuera una cucaracha, pues el principio de identificación imaginaria también está en los animales.

En el ser humano la identificación imaginaria es una condición de posibilidad para el surgimiento del lenguaje. Que tanto en el animal como en el ser humano haya un principio de reconocimiento es interesante, pero en el caso del ser humano este principio va en otra dirección. En los animales surge un «inter-reconocimiento", mientras que en el ser humano hay un autorreconocimiento y este —auto-reconocimiento — que emerge del reconocimiento de sí mismo en el otro- abre la posibilidad para que aparezca el lenguaje. 
¿Por qué alguien que ya manejaba el lenguaje y se desempeñaba en un mundo social tiene un acontecimiento que lo detiene frente a todo - el trabajo, la familia, etc.—, expresándose como una transformación, una ruptura o fragmentación en la consistencia del cuerpo imaginario? El nulo dominio que tiene Gregor sobre su cuerpo, a raíz de la transformación, evidencia una suerte de falla en la identificación del cuerpo imaginario, lo que pone en crisis el reconocimiento, pues su transformación en bicho no da cabida para pensar en la identificación con la imagen. Esto muestra una ruptura en la consistencia del cuerpo que se da, a nivel imaginario, en la identificación con el otro. Así pues, el cuerpo imaginario producido por éste no está puesto de manera alguna para la identificación, lo que genera que no tenga control sobre su propio cuerpo:

Liberarse del cubrecama fue muy sencillo; le bastó con inflarse un poco y dejar que cayera por sí solo. Pero luego empezaron las dificultades, debido sobre todo a su descomunal anchura. Habría necesitado brazos y manos para incorporarse, pero en su lugar solo tenía esas numerosas patitas que no paraban de agitarse en todos los sentidos y que él, además, era incapaz de controlar. Si intentaba doblar alguna, esta era la primera que volvía a estirarse, y cuando por fin lograba hacer lo que quería con ella, las restantes proseguían, como abandonadas a sí mismas, con su extrema y dolorosa agitación (Kafka, 2012, p. 25).

\section{Pérdida del vínculo con el otro}

Paulatinamente Gregor va perdiendo la posibilidad de comunicación con los demás. No obstante, él todavía puede articular palabras en el pensamiento. Cuando el gerente llega a su casa y lo insta a dar explicaciones por su ausencia en el trabajo, Gregor se excusa, sin darse cuenta que sus palabras son ininteligibles para los demás, causando una reacción contraria a la esperada:

"¿Han entendido ustedes una sola palabra?», preguntó el gerente a los padres. «iEspero que no nos esté tomando el pelo!». «PPor el amor de Dios!», exclamó la madre llorando, «quizá esté gravemente enfermo y lo estemos torturando. ¡Grete! ¡Grete!», gritó luego. «¿Madre?», exclamó la hermana desde el otro lado. Se comunicaban a través de la habitación de Gregor. «Ve ahora mismo a llamar al médico. Gregor está enfermo. ¡Rápido, el médico! ¿Has oído cómo hablaba?». «Era una voz de animal», dijo el gerente en un tono sorprendentemente bajo comparado con el griterío de la madre (Kafka, 2012, pp. 34-35). 
Al momento de nacer nos hallamos supeditados a la voluntad del otro, o sea, estamos sujetos a aprender la lengua — cualquiera que sea - de aquel que ya está inscrito en el lenguaje, que maneja una lengua en específico y nos interpela al hablarnos, anticipando una respuesta. Por tener la creencia de que la interpelación verbal tiene lugar, volvemos hablante al recién llegado -a ese ser no hablante, pero con todas las posibilidades de serlo- . Al anticipar, no lo estoy convirtiendo deliberadamente en hablante, sino que el otro llega a ser hablante como producto de un efecto. Entonces, ¿cómo puede Gregor transformarse en un hablante, siendo un personaje — un ser- que no tiene ningún vínculo con el lenguaje?

Producido el sujeto hablante, atado al significante ${ }^{3}$, ahora se definirá en el lenguaje como una variable algebraica, como elemento que puede reemplazarse. Esto quiere decir que un sujeto aparece cuando un hablante se representa por un significante ante otro significante, lo cual implica dos cosas: 1) el sujeto es una variable significante en la que se produce un vaciamiento - los significantes están vacíos, su estatuto es diferencial (variable reemplazable)—; esto hace que 2) el sujeto entre en el encadenamiento significante; así, en sentido retroactivo, él obtiene su estatuto de sujeto por el hecho de inscribirse en la cadena significante. Pareciese, pues, que el Otro es el inconsciente hablando en mi cabeza, por lo cual no hay sujeto sin relación con el lenguaje, y las unidades del lenguaje surgirían del vínculo entre significantes. El sujeto es un significante más, no tiene ningún contenido, pero solamente lo que constituya una lengua — conjunto de elementos significantes — puede de facto producir a un sujeto. El contenido — que el sujeto no tiene en cuanto es una variable formal, algebraica - viene después como elucubración que el sujeto hace al darle contenido imaginario a lo que es una estructura formal:

El animal pasa por mudo porque sus formas de expresión no están ennoblecidas como «lenguaje». Pero, sobre todo, el animal no conoce el pudor: presenta su

\footnotetext{
El significante es un elemento diferencial, argumenta Jacques-Alain-Miller: «El significante sólo se plantea oponiéndose a uno o dos significantes diferentes. La única existencia de ese significante es esa oposición en sí misma. Se trata de un elemento que no tendría consistencia propia y que solo existiría por su diferencia con otros elementos del mismo tipo. Es pues un elemento no sustancial, que no puede ser descripto por sus propiedades intrínsecas, sino tan solo por diferencia. Entonces es un elemento no sustancial diferencial» (1988, p. 12).
} 
cuerpo en un modo que recuerda constante y penosamente al hombre su propia animalidad. La consecuencia es la náusea, el asco físico y la violencia contra ese pariente demasiado próximo (Stach, 2003, p. 242).

La susceptibilidad para hablar está dada por la relación imaginaria. Si el contenido viene después como elucubración, ¿qué es lo que tenemos antes?: la forma, el significante, pues éste no es contenido, es mera forma; Saussure diría: «[L]a lengua es una forma y no una sustancia» (1987, p. 142), es decir, la lengua es un sistema de signos que se diferencian entre sí, es una estructura formal, si se quiere; no obstante, no tiene un contenido intrínseco o inherente a él... este viene a posteriori. El contenido aparece después como elucubración en el estatuto imaginario. El cuerpo que creamos en la identificación con el otro lo expandimos al mundo, es decir, el mundo ya está marcado por la significación del cuerpo, por la elucubración que hemos hecho a partir de tener un cuerpo. No es raro considerar que la aversión, la repugnancia que causa Gregor en los demás, es suscitada porque la transformación lo deja sin la posibilidad de identificarse con otro y de ser identificado. Es por esto que el horror juega con los límites de la identificación, no de la diferencia:

Un insecto del tamaño de un niño es una idea espantosa, y dentro de su marco narrativo Kafka casi no ha dejado pasar ocasión alguna de intensificar aún más ese impacto. Cuando hace trepar al escarabajo por las paredes y el techo, no es solo, en absoluto, para demostrar el alejamiento de Gregor de su vida humana anterior, sino sobre todo para mantener el espanto vivo en el lector. A la misma finalidad sirven los detalles físicos tercamente recurrentes, que provocan asco e impiden al lector constantemente sublimar de alguna manera su horror y disfrutar de La metamorfosis como [...] la historia de una sublime catástrofe espiritual. No sorprende que en momentos de distancia el propio Kafka considerase su obra «excepcionalmente nauseabunda» incluso antes de haberla terminado (Stach, 2003, p. 253).

Cuando viene el significante hacemos cierta relación entre elementos significantes, produciendo un efecto de significación; dicho efecto de significación está en lo imaginario. El paso de lo imaginario es la invención del cuerpo como cosa en la que me alieno, siendo una creación, un mundo posible que aparece porque la relación visual conmigo mismo no era una relación de reconocimiento. Cuando aparece el lenguaje, hago de ese cuerpo otra cosa, un 
mundo imaginario en el que se depositarán las elucubraciones que hago. El sentido tiene que ver con la imagen y, por tanto, el campo de lo imaginario sería una especie de expansión del cuerpo que le da sentido a eso que veo.

¿Qué sucede con Gregor? Si el sujeto es un significante que remite, necesariamente, a otro significante, ¿qué estatuto hay para él luego de la transformación? El sujeto es sujeto del significante, se relaciona con el lenguaje en cuanto él es una variable significante y el contenido ahí no cuenta sino como elucubración que se produce. En otras palabras, sólo puede haber contenido a condición de que haya estructura formal, significante. Esto ya está dicho desde la idea de la Modernidad: el sujeto como variable significante — sin un sentido constitutivo- evidencia que la ciencia asume como objeto de investigación el cuerpo del sujeto - mas no el sujeto como tal, aunque esto no deja de ser plausible en la medida en que ya no nos morimos tan fácilmente de tuberculosis, por ejemplo—. La gramática, v. gr., es un sistema significante que sirve de base para la edificación de una lengua, sin importar cuál. En suma, para que alguien se «inscriba» en el juego del lenguaje tiene que ser interpelado por otro que da por sentado que aquel al que le habla en algún momento llegará a responderle.

El lenguaje solo, como estructura, no interpela a los sujetos, hay que tener sujetos que puedan interpelar $r^{4}$. Pero es en el equívoco de interpelar a un niño, considerando que es un sujeto, que existe la posibilidad de poder atraerlo o seducirlo para que articule palabra, entienda, forme enunciados y, finalmente, hable.

En esta relación aparece el deseo, tanto del lado del sujeto que le habla al niño y desea que este hable, como del lado del niño que puede desear hablar. Por ello, el sujeto es efecto lógico del lenguaje, esto es, el lenguaje es constitutivo del sujeto. Lo imaginario da un cuerpo, y éste da la opción de inscribirse en el lenguaje. De tal manera, sabemos que Gregor obtuvo un cuerpo y, por eso, tenía una vida en lo social, era reconocido, aprendió a hablar. Así, aunque la transformación haya afectado su cuerpo, sigue existiendo en lo simbólico, sigue pensando.

«[... oyendo a los demás es como aprendemos nuestra lengua materna» (Saussure, 1985, p. 33). 


\section{La transformación como el desborde de lo real}

La intranquilidad en el sueño tiene que ver con el advenimiento de lo real. El cuerpo real es singular, no es medible ni universalizable. No hay una medicina o una intervención para sacar al personaje de su impasse. Por eso, el cuerpo que resulta de la transformación aparece como indeterminado, ambiguo; por ende, el narrador lo llama «bicho» y no «escarabajo» o «cucaracha». Pero, ¿por qué sucede esto? Veámoslo por sus efectos: el protagonista busca una manera de tramitar su pulsión, de arreglárselas con ella, y entonces produce —así como producimos sueños - un cuerpo monstruoso con el que nadie puede identificarse, pero que, a su vez, divide al personaje.

La pulsión se tramita de una u otra manera, pero en este caso se tramita de una forma que pone en crisis la ligadura entre lo imaginario, lo real y lo simbólico. Esto desborda al personaje, al punto de que la tramitación no pasa por aunar los tres registros, sino que pone en primera medida a lo imaginario (I), desanudado de lo simbólico (S) y de lo real (R). Gregor está desbordado por la imagen, no tiene una explicación o una justificación sobre ella.

Usualmente, los tres registros están anudados como un nudo borromeo —si se suelta cualquiera de ellos, se sueltan los otros dos-5:

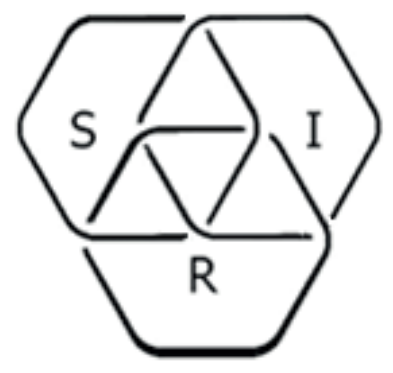

Ahora bien, la transformación parece haber desanudado el registro imaginario, ante lo cual Gregor anuda lo simbólico a lo real:

Creación propia. 


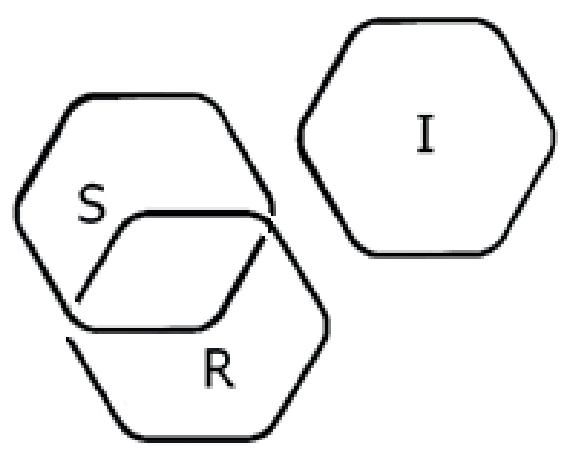

Con este desanudamiento parcial, Gregor aparece ante el otro como alguien que exhibe la pulsión, no simplemente una forma — bicho-, lo cual es un agravio para los semejantes. Efectivamente, la transformación explicita su singularidad a partir de lo pulsional. Y, finalmente, esta irrupción desarreglará el anudamiento entre los tres registros:

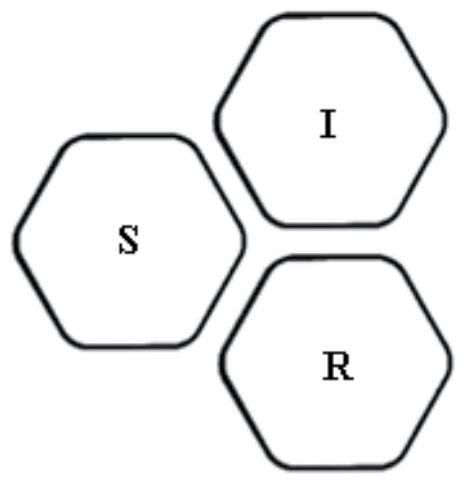

De ahí que se pueda asumir que la materialización del goce del cuerpo de Gregor a través de un bicho monstruoso es un acontecimiento que lo sobrepasa y patentiza el modo en que goza — se satisface—, aunque no quiera saber de ello y trate, a como dé lugar, de eludirlo: “¿广Y si durmiera un rato más y me olvidara de todas estas tonterías?»” (Kafka, 2012, p. 20), dice. Aunque no quiera hacerse responsable de aquello en que se ha convertido — siempre hay una respuesta por parte del sujeto, pues somos responsables aun de lo que no hemos dicho, de los acontecimientos, de lo que no hemos pensado, porque 
frente a ello asumimos una postura y ésta es la que nos define como sujetos y muestre un padecimiento, un sufrir, no podemos obviar que Gregor goza; goce que se expresa como sintomático: hace padecer y se sustenta en la materialidad del cuerpo ${ }^{7}$. Al tiempo que sufre, satisface la pulsión.

La pulsión arremetió de tal forma que alteró el anudamiento entre los registros, con lo cual el cuerpo quedó arrojado al estatuto del «no-reconocimiento». El acontecimiento es de satisfacción pulsional, que Gregor asume por la vía del pensamiento: no puede dejar de pensar. Él no goza solamente del cuerpo, goza también del pensamiento - lo simbólico-. Con la transformación, ¿`se las arregló para estar en una situación en la que ya no hay que contar con el cuerpo y se puede gozar con el pensamiento? Parece, entonces, que la modalidad de relación que tiene con el goce no pasa por el cuerpo, sino por la palabra.

El cuerpo es el lugar donde recaen los efectos del síntoma, una vía diferente a la asumida por la ciencia, la medicina, la fisiología, que comprenden el cuerpo como soporte objetivo de investigación. De modo que el síntoma puede ser asumido como una consigna del inconsciente, un mandato u orden del inconsciente en calidad de amo, en el que el sujeto se ve supeditado a éste, posicionándolo como esclavo de la consigna ${ }^{8}$. En el síntoma, el sujeto goza del sufrimiento de su propio cuerpo, evidenciando el goce en la extralimitación del principio del placer. El goce es la satisfacción de la pulsión, lo cual tiene

6. Respecto al anudamiento de los registros simbólico, imaginario y real, que remite singularmente a cada uno de nosotros, se constituye la dimensión subjetiva. Ésta radica en lo que hacemos con dichos registros, en la manera que encontramos de anudarlos. Aquí vemos tanto la dimensión ética del actuar - y de lo que no se hace- como el sentido paradójico del goce.

7. «El síntoma está conectado al inconsciente, porta una verdad inconsciente del sujeto y al mismo tiempo es la forma en que cada uno goza de su inconsciente. En el síntoma, el inconsciente, el goce y el cuerpo se anudan» (Fuentes, 2016, p. 66).

8. «[E]n todas partes el arte aparece en sí mismo revestido de una inexpresable dignidad: es la tarea por excelencia, una tarea indiscutible, un mandato imperioso cuyo cumplimiento no puede rechazarse, ni siquiera diferirse» (Robert, 1980, p. 15).

9. Para comprender a qué hago alusión con la extralimitación del principio del placer, en primera medida es necesario saber qué se entiende por principio del placer; en términos freudianos: «El principio del placer es entonces una tendencia que está al servicio de una función: la de hacer que el aparato anímico quede exento de excitación, o la de mantener en él constante, o en el nivel mínimo posible, el monto de la excitación» (Freud, 1920, p. 60). Entretanto, desde Lacan el principio de placer tiene que ver con el goce de la palabra, por ende, el goce está más allá del principio del placer. Freud se da cuenta que hay algo de la satisfacción del sujeto que se obtiene justamente más allá del límite, entre otras razones gracias 
como efecto ciertas afecciones en el cuerpo. Además, bajo la supuesta insistencia de Gregor de pretender volver a trabajar pese a su condición subyace un no querer saber su situación. Por lo tanto, podemos decir que la máxima del goce de Gregor se encuentra en el «no querer saber eso». De ahí que el síntoma se asuma como la verdad que debemos escudrińar.

Adicionalmente - y no menos importante- el sujeto, que es objeto de la dictadura del inconsciente, está concernido. Esto quiere decir que es un mandato de su inconsciente — no es el inconsciente de otro- que le compete y por el que debe responder. El inconsciente le formula al sujeto ciertos enunciados que lo someten, lo convierten en objeto de goce, por consiguiente, hay una escena de satisfacción, ya no es sólo el inconsciente, pues también se alude a la pulsión. El sujeto se satisface ante la sumisión a su inconsciente, se vuelve esclavo del mismo, pero goza del enunciado que erige el inconsciente. Hay, entonces, una estructura de enunciación opresiva en el sujeto mismo.

Para Lacan, «ningún lenguaje podría decir lo verdadero sobre lo verdadero, puesto que la verdad se funda por el hecho de que habla, y puesto que no tiene otro medio para hacerlo» (2002, p. 846), por lo tanto, el cuerpo —en cuantosintomático habla, dándole voz al inconsciente, el cual «dice lo verdadero sobre lo verdadero, está estructurado como un lenguaje» (2002, p. 845). Así pues, todos los cuerpos gozan y los sujetos deben lidiar con su síntoma, sin olvidar que no hay modalidad de goce igual a la de otro. El cuerpo está amarrado al lenguaje, de manera que, ya de entrada, decir cuerpo es decir cuerpo hablante, a saber, cuerpo de un ser que habla; por ende, el movimiento del cuerpo ya es - de alguna manera- un enunciado. Pero enunciado que no es del mundo «transparente» de las cosas, no es claro y distinto, es, por el contrario, un enunciado a través del lenguaje, que emana de un nudo, un enredo, en el que ese lenguaje no dice exactamente el cuerpo y ese cuerpo «intenta» hablar.

La capacidad de hablar de un sujeto, en realidad, implica que la lengua habla por medio de él, pues fue inducido por otros hablantes bajo una estructura que lo precede. Al respecto podemos citar a Heidegger: «El hombre se comporta como si fuera él el creador y el maestro del lenguaje, cuando en

a que hay un límite. Dado que el cuerpo sintomático rompe la homeostasis, en este sentido se habla del más allá del principio del placer, o bien de la extralimitación del mismo. 
realidad es el lenguaje el que se adueña del hombre» (2015, p. 15). No hay sujeto sin síntoma: estamos hablando de un sujeto que se encuentra en una relación problemática con el lenguaje. El cuerpo imaginario que erigió y posibilitó que hablara produce marcas del lenguaje que se inscriben en el cuerpo real, las cuales hablan su "propio idioma»" ${ }^{10}$ en el inconsciente, lo que tiene como resultado que el cuerpo termine completamente comprometido con el lenguaje por medio de una consigna que es el síntoma. Cuando el sujeto se relaciona con el lenguaje, hay ya en éste una estructura que lo excluye, v. gr., la gramática ya está y no introduciremos nada en ella, esto es, nada personal va a alterar la gramática. Dicho de otra manera, el hecho de «unirnos» al lenguaje es, en sí mismo, un acontecimiento sintomático; en consecuencia, el síntoma es constitutivo del ser hablante.

Gregor es un sujeto sintomático, hablado por la lengua que no resistió y es atropellado por ese goce que ya no podía encontrar lazo con lo simbólico y lo imaginario, desbordándose por la vía de lo real, pues literariamente es la conversión de un hombre en un bicho. Dado que el cuerpo se presenta como una multiplicidad, nos ocupamos de una perspectiva diferente a la de los propósitos de la ciencia moderna, la cual busca establecer una relación entre el sujeto y el saber; saber que formaliza, cuantifica, contabiliza el cuerpo. La operación lógica de la ciencia es la asunción del sujeto como significante para poder tener un objeto de investigación: el cuerpo, al ser objeto de estudio, ha permitido que hoy en día exista una diversidad de curas para enfermedades que antaño hacían perecer a millones de seres humanos, no obstante, esta actividad deja un resto, un sujeto que está vinculado de manera enmarañada con su cuerpo.

Ahora bien, una propuesta conveniente para el objetivo de este artículo, y en consonancia con lo argumentado, es la película rusa Превращение Prevrashchenie - (Bits et al., 2002) inspirada en La transformación. Allí vemos al actor Evgeniy Mironov — quien representa a Gregor Samsa— vivenciando la experiencia de ser un bicho, pero manteniendo la morfología de hombre. Esta adaptación cinematográfica hace compatible la interpretación de la trans-

10. El inconsciente habla en sueños, equivocaciones, olvidos, chistes, etc. No controlamos el lenguaje, sino que éste se nos instala como inconsciente y habla su propio idioma. Tenemos cierto control sobre la palabra, pero de alguna forma el lenguaje nos controla a nosotros. 
formación de Gregor como producto de un fenómeno onírico y, por ende, una manifestación de su inconsciente. La transformación es producto de su inconsciente; una vez más encontramos la semejanza entre el sueño y la alucinación literaria. Freud sostendrá que:

[...] el excitador del sueńo es un deseo, y su cumplimiento es el contenido del sueño, esto constituye uno de los caracteres principales del sueño. [...] el sueño no expresa simplemente un pensamiento, sino que figura ese deseo como cumplido en cuanto vivencia alucinatoria (Freud, 1978, p. 118).

Esto puede significar que la transformación de Gregor es un cumplimiento de un deseo.

Los rasgos de la transformación, de la fractura imaginaria, se encuentran explícitos, en parte, por el agite de las patas del cual es preso y los demás elementos que aluden a la imagen. En el ámbito onírico, todo esto está recubierto por lo simbólico; así, elementos referidos al cuerpo real terminan sirviendo de sustento para el contenido simbólico-imaginario de los sueños. Por eso asumimos la transformación como el desborde de lo real. De hecho, en ciertas ocasiones, cuando tenemos algún malestar corporal mientras dormimos, el sueño lo disfraza, poniéndolo en relación con el contenido del sueño. De la misma manera, una atmósfera simbólica recubre el asunto corporal de Gregor.

\section{Conclusiones}

En una aproximación al texto La transformación, mediante el uso del psicoanálisis como herramienta, hallamos que la creación literaria tiene tintes de alucinación que son de un matiz muy semejante al de los sueños. Se habló, en primera medida, a partir de la constitución de la autoconciencia en el reconocimiento con otra autoconciencia; y, en segunda, de la identificación por vía imaginaria del propio cuerpo a través de la imagen del cuerpo del otro.

El reconocimiento conlleva la agresión y la identificación imaginaria a la posibilidad de ser hablante. El cuerpo imaginario está absolutamente modificado en la transformación de Gregor Samsa, pero él no se ocupa de ese cuerpo. 
El recurso de Gregor, en el orden de una cierta modalidad de satisfacción, es el de imponer la lógica simbólica como para decir «aquí no ha pasado nada», "puedo seguir pensando como antes», «lo que me ha ocurrido es un accidente que puede rehacerse»; esto es, Gregor opta por quedarse gozando del pensamiento, de la palabra. En tercera medida, hay unos anuncios del cuerpo real de Gregor: la transformación es el desbordamiento por vía de lo real, de lo pulsional, que genera un cuerpo con el que nadie se identifica y que, a su vez, lo divide. Asimismo, hay una adaptación al cuerpo de bicho, lo cual implica ir perdiendo, paulatinamente, el vínculo social a través del lenguaje. De ese modo, Gregor Samsa evidencia un sujeto dividido, sintomático.

En definitiva, de lo anterior podemos concluir que todo aquel que se encuentra sumido en la creación literaria no tiene total control sobre el texto, pues, por un lado, está la instancia volitiva que lo lleva a escribir, y, por otro, su inconsciente también lo impele a hacer este ejercicio. Por lo tanto, la literatura tiene vestigios del inconsciente.

\section{REFERENCIAS}

BioDic (2019). Diccionario de Biología. Recuperado de https://www.biodic.net/palabra/metamorfosis/\#.XOHW-iD0nIU

Bits, L., Lerner, O., Pogrebinsky, I. (productores) y Fokin, V. (director) (2002). Prevrashchenie (Metamorphosis) [Película]. Rusia: Vsevolod Meyerhold's Creative Center.

Borges, J. (3 de julio de 1983). Un sueño eterno. El País. Recuperado de https://elpais. com/cultura/2015/04/09/actualidad/1428570964_294931.html

Freud, S. (1978) [1915-1916]. «Conferencias de introducción al psicoanálisis (partes I y II)». En Obras completas. Vol. xv (pp. I I 5-I 24). Buenos Aires: Amorrortu.

Freud, S. (1979) [1920]. «Más allá del principio de placer». En Obras completas. Vol. XVIII (pp. I-62). Buenos Aires: Amorrortu.

Freud, S. (1990) [1929]. «Malestar en la cultura». En Obras completas. Vol. xxI (pp. 57-I40). Buenos Aires: Amorrortu. 
Fuentes, A. (2016). El misterio del cuerpo hablante. Barcelona: Gedisa.

Hegel, G. (1985). Fenomenología del espíritu. México: Fondo de Cultura Económica.

Heidegger, M. (2015). Construir, habitar, pensar. Madrid: Oficina de Arte y Ediciones.

Kafka, F. (1974). La metamorfosis. Madrid: Alianza.

Kafka, F. (2004). Die Erzählungen und andere ausgewählte Prosa. Leck: Claussen \& Bosse.

Kafka, F. (2010). La metamorfosis. En F. Kafka, La metamorfosis y otros relatos de animales (pp. 41-97). Barcelona: Austral.

Kafka, F. (2012). La transformación. Bogotá: Géminis.

Lacan, J. (2002). «El estadio del espejo como formador de la función del yo [je] tal como se nos revela en la experiencia psicoanalítica». En Escritos II (pp. 99-106). Buenos Aires: Siglo XxI.

Lacan, J. (2008). «La ciencia y la verdad». En Escritos I (pp. 813-836). Buenos Aires: Siglo XXI.

Miller, J.-A. (1988). Matemas II. Buenos Aires: Manantial.

Robert, M. (1980). Acerca de Kafka. Acerca de Freud. Barcelona: Anagrama.

Saussure, F. (1987). Curso de lingüistica general. Madrid: Alianza.

Saussure, F. (1985). Curso de lingüistica general. Barcelona: Planeta DeAgostini.

Stach, R. (2003). Kafka. Los años de las decisiones. Madrid: Siglo xxi.

Wetter, N. (5 de abril de 2015). Der Buchmschlag der Verwandlung: nur kein Käfer! Franz Kafka: Die Werwandlung. Recuperado de https://nataschawetter.wordpress.com/2015/04/05/der-buchumschlag-der-verwandlung-nur-kein-kafer/ 